\title{
IV-я СЕССИЯ МЕЖДУНАРОДНОЙ ШКОЛЫ КОРМОВ
}

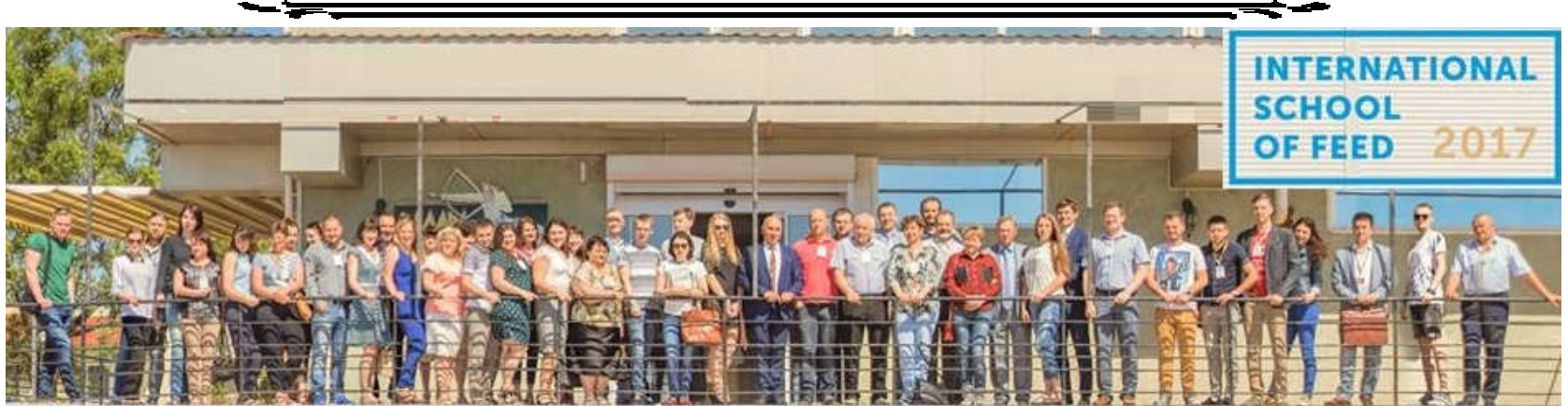

29 мая - 04 июня 2017 г. в рамках IV-ой сессии Международной школы кормов, организованной Одесской национальной академией пищевых технологий (ОНАПТ), проведено два тренинга:

- Тренинг 1: «Искусство создания высокоэффективных рецептов комбикормов»;

- Тренинг 2: «Внутренний аудит и оценка схемы GMP+FSA в соответствии с требованиями стандартов GMP+B1 "PRODUCTION, TRADE \& SERVICES” и ISO 19011:2011».

B работе тренингов приняли участие специалисты-производственники и ведущие ученые Украины, России, Белоруссии, Сербии, Швеции и Англии в области производства и анализа комбикормов, кормления сельскохозяйственных животных и переработки животноводческой продукции. Проблематика тренигов была посвящена новым тенденциям в области продаж и совершенствования технологий производства комбикормов и добавок, анализа и оценки качества сырья и готовой продукции, и освещалась в докладах спикеров, практических занятиях по расчету и оптимизации рецептов комбикормовой продукции.

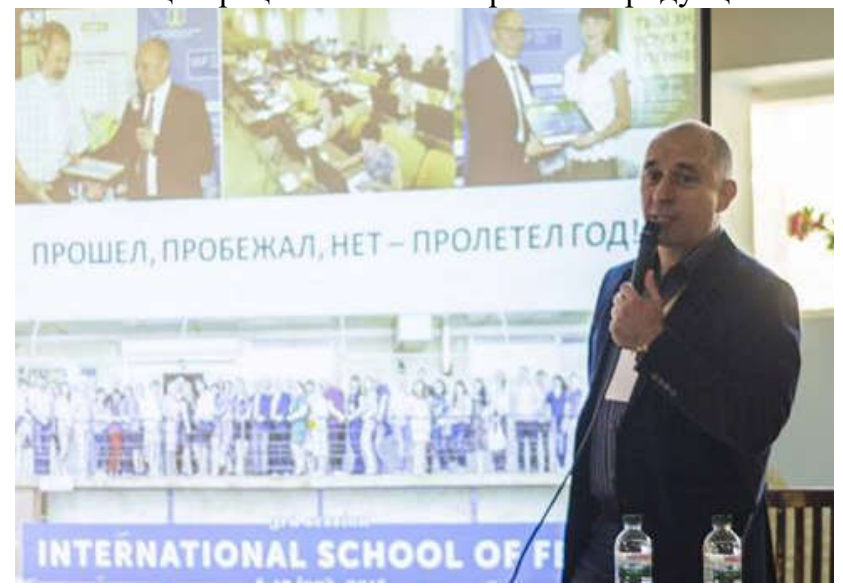

Открыл IV-ю сессию МШК со вступительным словом профессор Богдан ЕГОРОВ, д.т.н., чл.-корр. НААН Украины, заслуженный деятель науки и техники Украины, лауреат Государственной Премии Украины в области науки и техники, и.о. ректора ОНАПТ, который также представил информацию о деятельности Ассоциации «Союз кормопроизводителей Украины» и «Клуба молодых ученых ОНАПТ» за 2016-2017 годы.

Доклад Вадима ШИЯНА, Председателя Совета директоров ГС Межрегиональный Союз птицеводов и кормопроизводителей Украины, был посвящен приоритетным направлениям развития малых и сред-

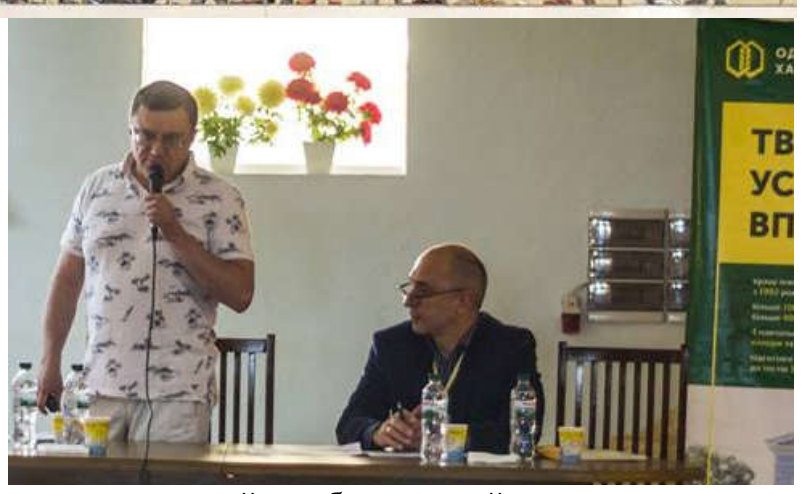

них предприятий комбикормовой отрасли, а именнореализации Проекта «Марокко - ворота в Северную Африку, как развитие экспортного потенциала украинских производителей». Реализация проекта позволит обеспечить экспертное сопровождение ВЭД; организовать деловые поездки, бизнес-встречи, выставки, форумы по вопросам кормления и содержания птицы и животных (на базе предприятий членов Союза); конференции, симпозиумы в Украине и за рубежом. В июле запланирована выставка птицеводства, животноводства и кормов в Стамбуле VIVТурция.

Руководитель проекта GMP+ в Украине Татьяна КОПНЯК рассказала про значимость безопасности кормов, развитие схемы GMP+ FSA на рынке, особенности сертификации кормов GMP+, про основные вызовы и возможности для украинских компаний в области кормопроизводства.

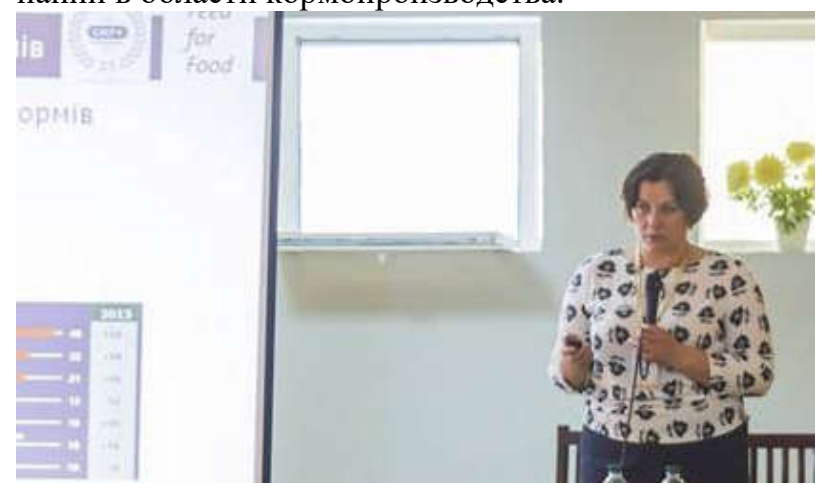

Об интеллектуальной системе пробоотбора сырья комбикормов - GMIAN (Grain Mix Analyzer) рассказал в своем докладе Виктор ЕГОРОВ, к.т.н., ассистент кафедры Автоматизации технологическихпроцессов и робототехнических систем ОНАПТ. Проведена презентация сервиса, состоящего из пробоотборников, подключенных через облако к стационарному мультиспектральному анализатору, позво- 


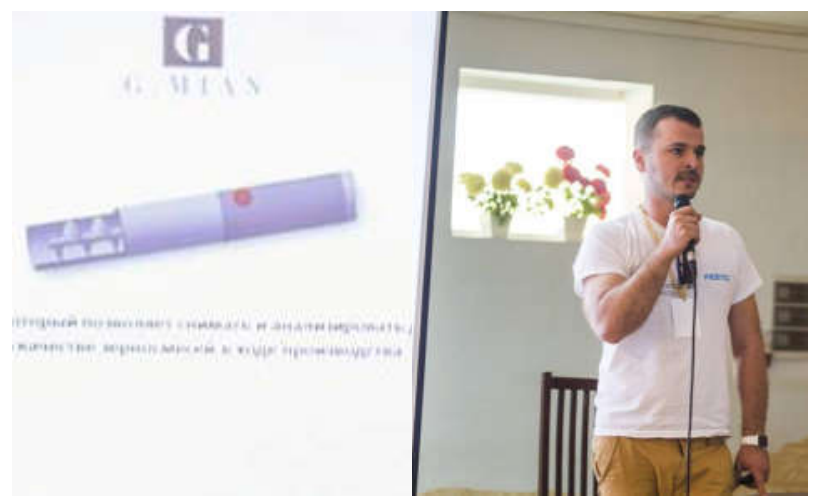

ляющего в течение 1 минуты провести полный анализ сырья/готовой продукции. Пробоотборник был представлен ОНАПТ на выставке в Hannover.

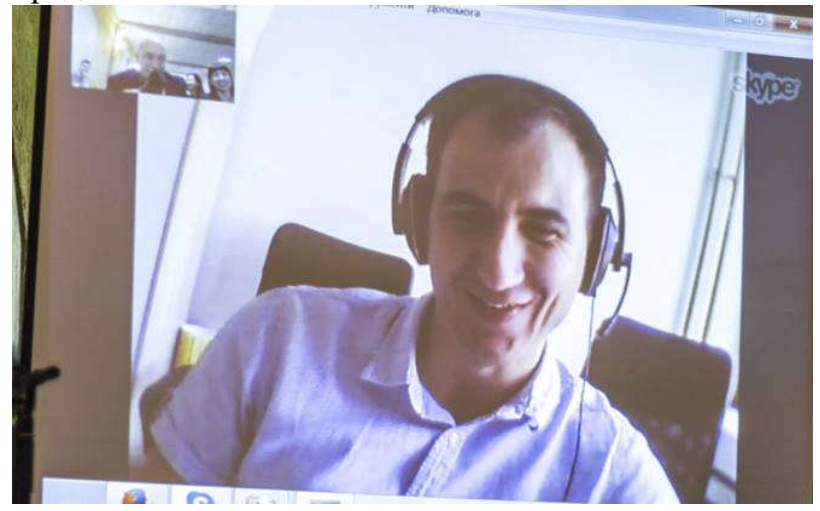

Про основные инновации технологического центра исследования комбикормов Института пищевых технологий университета Нови Сад (Сербия) и взаимное сотрудничество с ОНАПТ рассказал доктор наук Radmilo COLOVIC.

С ярким докладом перед участниками МШК про эффективные инструменты для достижения успеха в бизнесе и торговле выступил тренер-практик Евгений ЛЕГКИЙ, бизнес-тренер компании Legkiy Business Centre, собственник TM WellWash директор по продажам компании ERA MG.

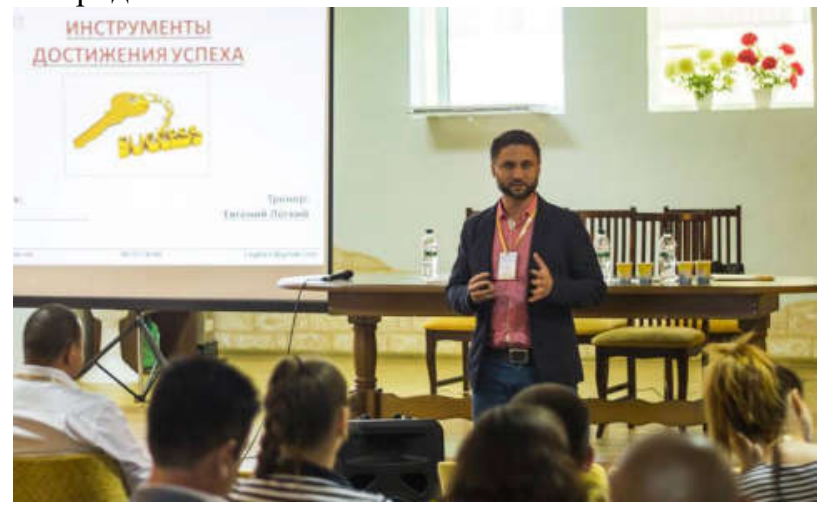

Про оценку эффективности технологических процессов и развития технологии производства комбикормов, проблемы и их решения, влияние на качество продукции, оценку технологический процессов были посвящены доклады проф. Богдана ЕГОРОВА, д.т.н., чл.-корр. НААН Украины, заслуженного деятель науки и техники Украины, лауреата Государственной Премии Украины в области науки и техники, и.о.ректора ОНАПТ.

В докладе генерального директора компании SocTrade, Швеция, Украина, SE, UA Александра ПЛЕВЕ речь шла об использовании ИК-анализаторов

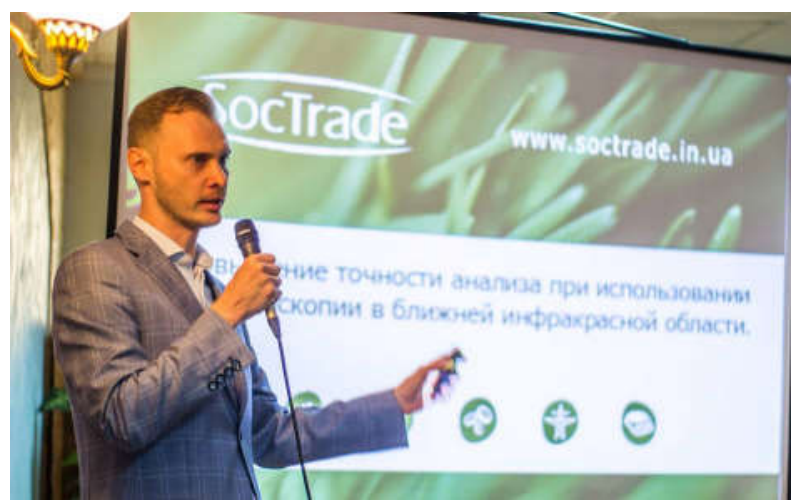

для измерения физико-химических показателей в условиях повышенных требований к точности, а также комплексный контроль БВМД и показателей безопасности кормов.

Для учасников тренинга в течение трех дней специалисты компании SocTrade проводили мастерклассы по определению физико-химического состава и токсичности комбикормов и кормового сырья на приборах: Inframatic 8800 - портативный ИК-анализатор целого зерна и семян масличных для оперативного контроля показателей качества урожая в месте отбора проб; Inframatic 9500 - ИК-анализатор целого зерна и семян масличных культур с дополнительным модулем для измерения продуктов помола; DA7250 - универсальный ИК-анализатор за 6 секунд анализирующий: зерновые, масличные, шроты и жмыхи, мука, крупа и отруби, мясокостная и рыбная мука, комбикорма рассыпные и в гранулах, древесные пеллеты; Aquamatic - стационарный и портативный высокоточные анализаторы влаги целого зерна; StatFax - фотометр для количественного определения токсичных веществ, аллергенов и микотоксинов в сырье и готовых комбикормах; AccuScan Gold - компактный фотометр для определения содержания микотоксинов в зерне и продуктах его переработки; Reveal $\mathrm{Q}^{+}$- наборы для определения содержания микотоксинов в течение 15 минут; СР4 - наборы Neogen для качественного определения содержания ГМО в кукурузе и сое; SER148/3 - автоматический экстрактор жира от Velp анализ единовременно в трех или 6пробах; FoodLab Touch - экспресс анализатор важнейших показателей качества пищевых продуктов.

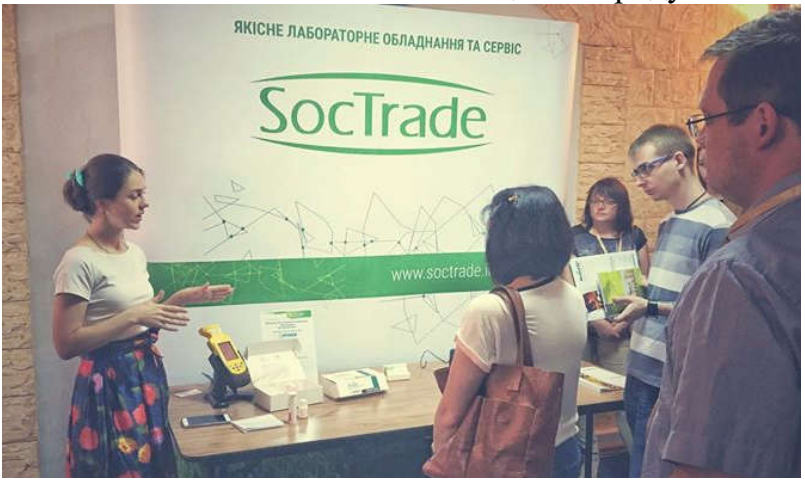

Использование системы Skype позволило в онлайн-режиме для слушателей МШК провести серию докладов про возможности повышения эффективности кормового потенциала комбикормов. Д.б.н, профессор Peter SURAI (профессор биохимии питания сельскохозяйственного университета Годолло, Венгрия; профессор эволюционной биологии и эко- 


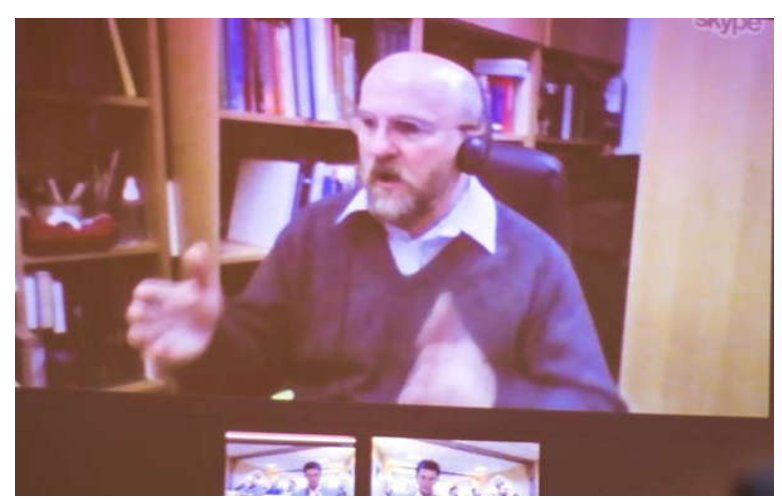

логии университета Глазго, GB) рассмотрел вопросы физиологии кормления сельскохозяйственных животных и птицы и способы их управления; использования БАВ как биокорректоров в кормлении сельскохозяйственной птицы и животных.

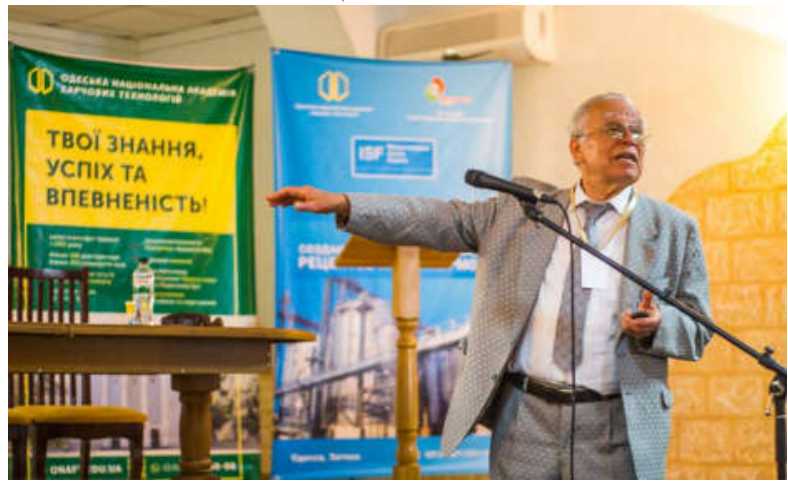

Про роль жирового питания в обеспечении жизнедеятельности сельскохозяйственной птицы и животных, их продуктивности и качестве продукции, речь шла в докладах д.б.н., чл.-корр. НААН Украины, профессора Анатолия ЛЕВИЦКИЦКОГО, Председателя Правления Научно-производственной ассоциации «Одесская биотехнология». На выставке были представлены основные разработки НПА «Одесская биотехнология» в области создания биологически активных добавок, которые вызвали значительный интерес и обсуждение у участников МШК.

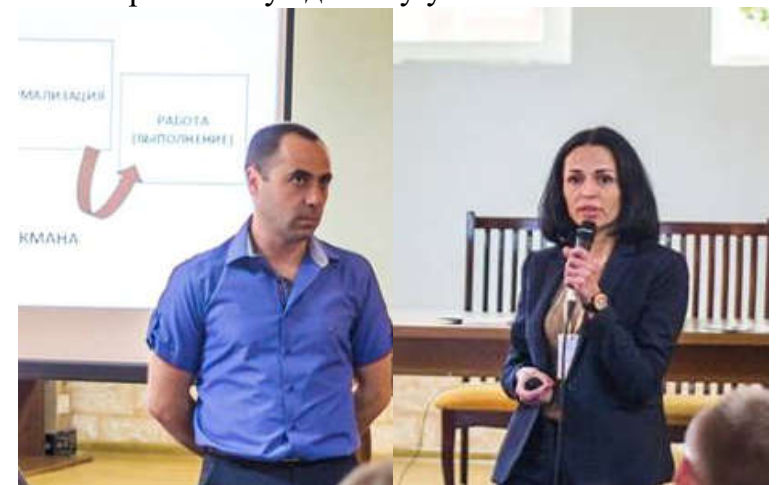

Нестандартным подходом в организации программы для слушателей МШК было участие в программе-интенсив, посвященной управлению конфликтами на основе эмоционального интеллекта, которую провела к.э.н, тренер-практик Екатерина КОЗАК, бизнес-консультант, руководитель агентства обучения и персонального консалтинга, доц. кафедры Менеджмента и логистики ОНАПТ. Участие в программе-интенсив вызвало большой интерес у участников во время создания определенных конфликтных ситуаций, способов разрешения и выхода из них.

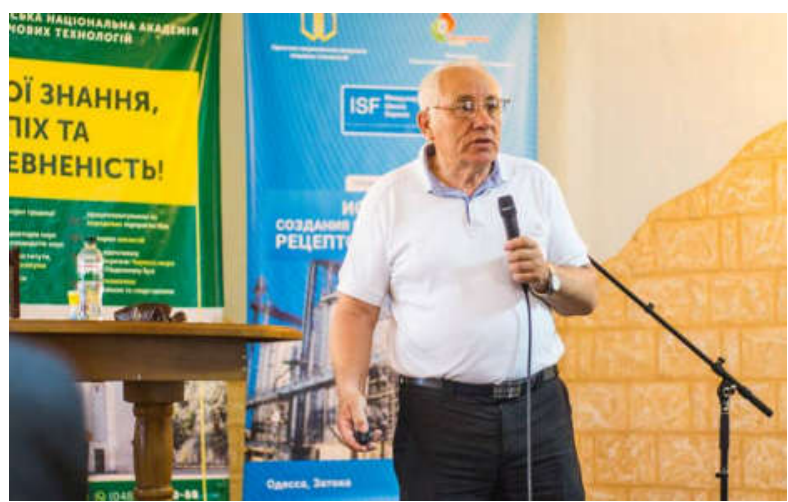

Особенностям сбалансированности комбикормов и факторам разбалансированности был посвящен доклад д.т.н. Ивана ПАНИНА, генерального директора OOO «Корморесурс», RU. В докладе детально рассматривалась роль базы данных программы «Корм-оптима» и ее характеристика, в качестве примеров была представлена оптимизация программ кормления для сельскохозяйственной птицы (бройлеры, несушка, индейки), свиней и крупного рогатого скота.

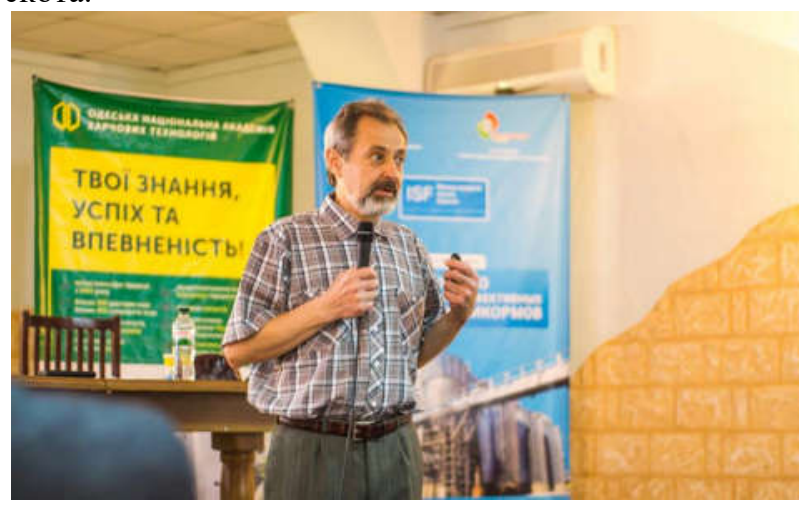

В докладе зам. директора по научной работе ООО «Биоконтакт», ЧП «Кронос-Агро», UA, к.б.н. Федора МАРЧЕНКОВА речь шла об особенностях применения пробиотиков в кормлении сельскохозяйственных животных и птицы.

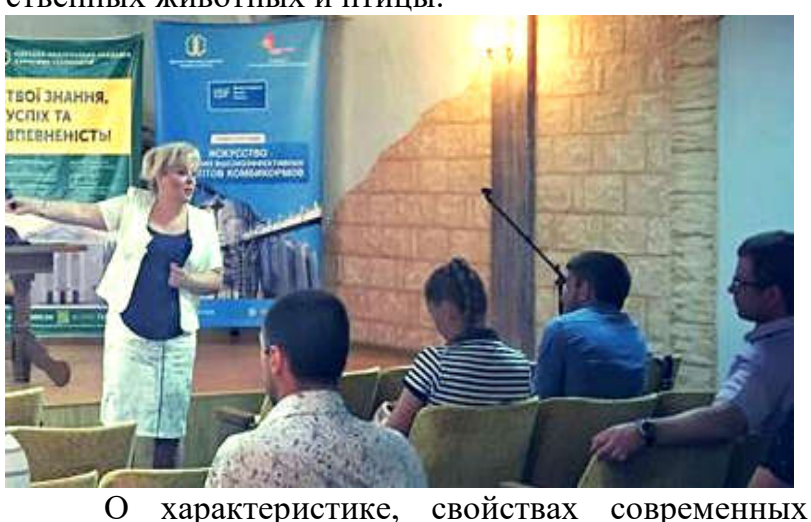
форм биологически активных веществ и развитии технологических методов обогащения комбикормов различными видами сухих и жидких форм БАВ, а также практических способов их реализации на действующих заводах Украины шла речь в докладе к.т.н, доцента Аллы МАКАРИНСКОЙ, и.о.зав.каф. Технологии комбикормов и биотоплива ОНАПТ, UA.

От лидеров промышленного производства комбикормов выступил с докладом генеральный директор ООО «FeedLife», UA Валентин КУЧЕРОВ, который рассмотрел научные основы и практический 


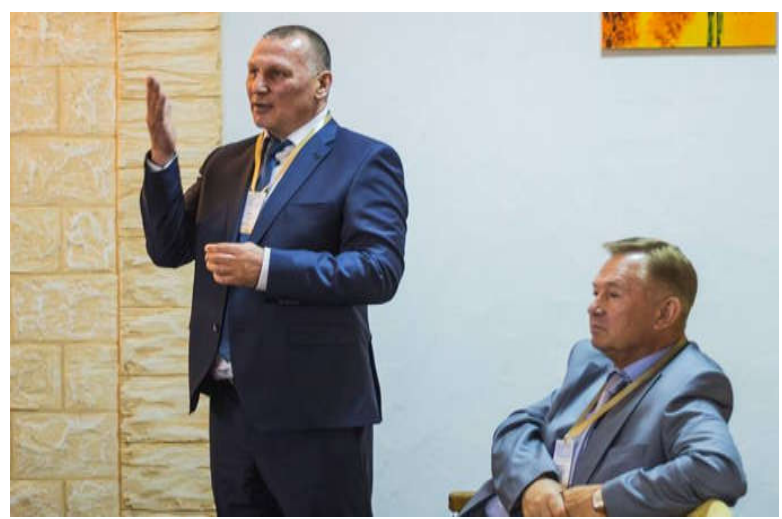

опыт производства высокоэффективных комбикормов на каждом технологическом этапе, пути повышения эффективности управления персоналом, производством и использованием комбикормов.

Закрепление теоретических положений и эксплуатации программы «КормОптима» проводилось на практических занятиях под руководством к.с.-Х.н. Василия ГРЕЧИШНИКОВА, ведущего программиста OOO «Корморесурс», RU. На общих и индивидуальных занятиях рассматривались вопросы, связанные с особенностями обновления баз данных о качестве компонентов для расчета рецептов комбикормов, работы с базами данных программы расчета рецептов комбикормов, основами расчета и оптимизации рецептов комбикормов с помощью программы «Корм Оптима».

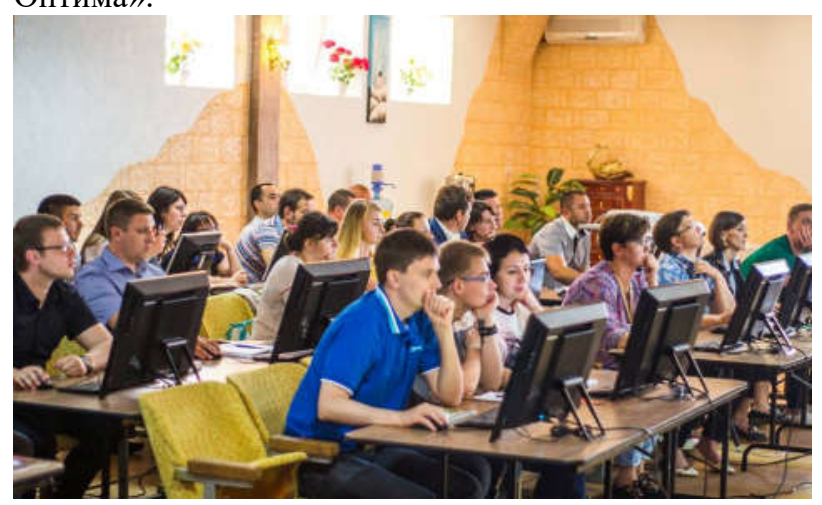

Каждый день работы МШК завершался вечерним дискуссионным клубом участников, где активно обсуждались перспективы внедрения информационных технологий в оценку качества комбикормов и

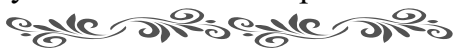

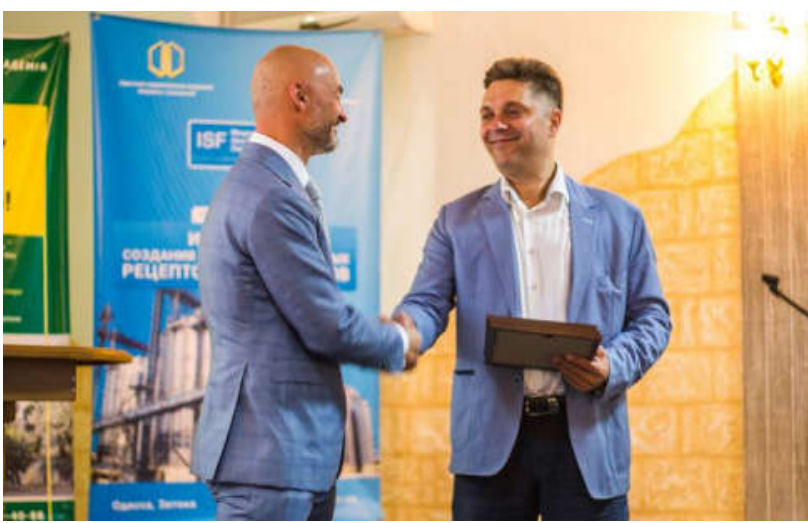

эффективность технологических процессов их производства; вопросы повышения эффективности использования человеческих, интеллектуальных, сырьевых, энергетических и финансовых ресурсов в борьбе за создание конкурентных рецептов и комбикормов.

Заключительным этапом работы МШК был индивидуальный практический экзамен по расчету и оптимизации рецептов и программ кормления сельскохозяйственной птицы и свиней.

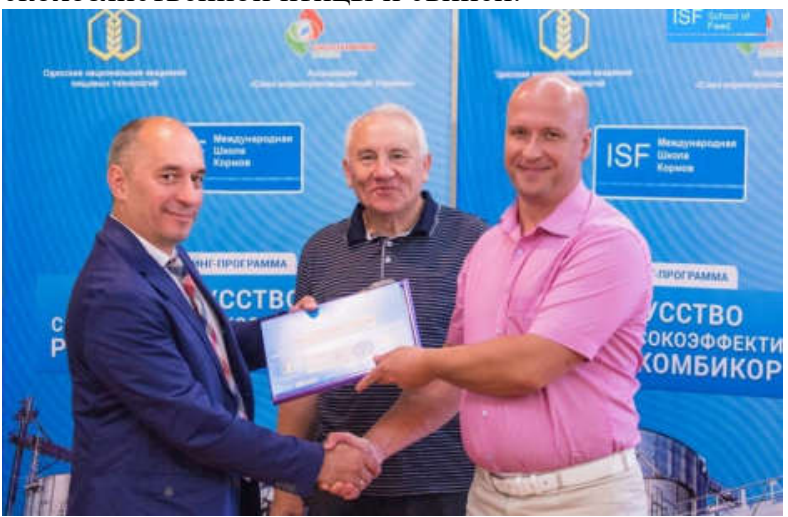

На научном Совете Международной Школы Кормов (ISF) после подведения итогов и результатов экзамена состоялось торжественное вручение Сертификатов участникам, успешно сдавшим практический экзамен. Праздничная церемония закрытия IV-й сессии Международной школы Кормов прошла на морском берегу.

Материал подготовили: Макаринская А.В., Фигурская Л.В. Поступила 09.06.2017. B печать 12.06.2017.

UDC 631.24:66:004.896

TRISHYN F.A. Ph.D., Associate Professor, FILIMONOV H.S. Master degree student Odessa National Academy of Food Technologies, Odessa

\section{AUTOMATION OF TRACEABILITY PROCESS AT GRAIN TERMINAL LLC "UKRTRANSAGRO}

\section{Abstract}

A positive trend of growth in both grain production and export is indicated. In the current marketing year the export potential of the Ukrainian grain market is close to the record level. However, the high positions in the rating of world exporters are achieved not only due to the high export potential, but also because of higher quality and logistics. These factors depend directly on the quality of enterprise management and all processes occurring at it. One of the perspective ways of enterprise development is the implementation of the traceability system and further automation of the traceability process. European integration laws are obliging Ukrainian enterprises to have a traceability system. Traceability is an ability to follow the movement of a feed or food through specified stages of production, processing and distribution. The process of traceability is managing by people, which implies a human 